УДК 579.678; 635-2

DOI 10.30679/2219-5335-2020-3-63-285-295

ИССЛЕДОВАНИЕ

ВЛИЯНИЯ ЭЛЕКТРОМАГНИТНЫХ ПОЛЕЙ КРАЙНЕ НИЗКИХ ЧАСТОТ НА ФИТОПАТОГЕНЫ ЗЕМЛЯНИКИ

Бабакина Мария Владимировна аспирант, младший научный сотрудник отдела хранения и комплексной переработки сельскохозяйственного сырья e-mail: wuhdz@mail.ru

Михайлюта Лариса Васильевна научный сотрудник отдела хранения и комплексной переработки сельскохозяйственного сырья e-mail: kniihp@mail.ru

Горлов Сергей Михайлович канд. техн. наук, доцент ст. научный сотрудник отдела хранения и комплексной переработки сельскохозяйственного сырья e-mail: gorlov76@ list.ru

Першакова Татьяна Викторовна д-р техн. наук, доцент вед. научный сотрудник отдела хранения и комплексной переработки сельскохозяйственного сырья e-mail: $7999997 @$ inbox.ru

Купин Григорий Анатольевич канд. техн. наук, старший научный сотрудник отдела хранения и комплексной переработки сельскохозяйственного сырья e-mail: griga_77@mail.ru
UDC 579.678; 635-2

DOI 10.30679/2219-5335-2020-3-63-285-295

\section{RESEARCH OF THE INFLUENCE OF ELECTROMAGNETIC FIELDS OF EXTREMELY LOW FREQUENCIES ON HYTOPATHOGENS OF STRAWBERRIES}

Babakina Maria Vladimirovna Postgraduate, Junior Research Associate of Storage and Complex Processing of Agricultural Raw Materials Department e-mail: wuhdz@mail.ru

Mikhaylyuta Larisa Vasilyevna Research Associate of Storage and Complex Processing of Agricultural Raw Materials Department e-mail: kniihp@mail.ru

Gorlov Sergey Mikhailovich Cand. Tech. Sci., Docent Senior Research Associate of Storage and Complex Processing of Agricultural Raw Materials Department e-mail: gorlov76@list.ru

Pershakova Tatyana Viktorovna Dr. Sci. Tech., Docent Leading Researcher of Storage and Complex Processing of Agricultural Raw Materials Department e-mail: 7999997@inbox.ru

Kupin Grigoryi Anatolyevich Cand. Tech. Sci., Senior Research Associate of Storage and Complex Processing of Agricultural Raw Materials Department e-mail: griga_77@mail.ru 


Краснодарский научно-исследовательский
институт хранения и переработки
сельскохозяйственной продукиии-
филиал Федерального государственного
бюджетного научного учреждения
«еверо-Кавказский федеральньий
научный иентр садоводства,
виноградарства, виноделия»,
Краснодар, Россия

Изучение и обобщение мирового опыта исследований посвященных разработке технологий, обеспечивающих снижение потерь, стабилизацию качества и максимальное сохранение биологически активных веществ продукции растениеводства в процессе хранения, позволило сделать вывод о том, что актуальными являются исследования по методологии применения электромагнитных полей крайне низких частот (ЭМП КНЧ) для контроля развития патогенной микрофлоры, приводящей к развитию заболеваний и как следствие потерям продукции растениеводства. В процессе исследования изучен состав микрофлоры земляники, установлено, что количество МАФАнМ на ягодах земляники сорта «Мармелада», урожая 2019 года составило от $5000 \mathrm{KOЕ} / \Gamma$ до 12000 КОЕ/г. КМАФАнМ в основном представлены споровыми микроорганизмами, энтеробактериями и дрожжами. Количество плесеней от $110 \mathrm{KOE} / г$ до $1400 \mathrm{KOE} / г$.

Исследовано влияние обработки электромагнитными полями КНЧ на патогены земляники грибковой природы. В образцах обработанных ЭМП КНЧ по сравнению с контрольным образцом количество микроорганизмов через 14 дней хранения было ниже.

Выявлены закономерности влияния параметров обработки ЭМП КНЧ на развитие патогенных микроорганизмов земляники в опытах и in vivo. Установлено, что обработки
Krasnodar Research Institute of Agricultural Product

Storage and Processing Branch of Federal State Budgetary Scientific Institution "North-Caucasus Federal Scientific Center of Horticulture, Viticulture, Wine-making», Krasnodar, Russia

The study and generalization of world experience in research on the development of technologies to reduce losses, stabilize the quality and maximize the preservation of biologically active substances of crop products during storage, made it possible to conclude that research on the methodology for the application of electromagnetic fields of extremely low frequencies (EMF ELF) is relevant. to control the development of pathogenic microflora, leading to the development of diseases and, as a consequence, the loss of crop production. During the study, the composition of the microflora of strawberries was studied, it was found that the amount of mesophilic aerobic and optionally anaerobic microorganisms (MAaOAM) on the berries of the strawberry variety «Marmalade», the harvest of 2019 , ranged from $5000 \mathrm{CFU} / \mathrm{g}$ to $12000 \mathrm{CFU} / \mathrm{g}$. MAaOAM are mainly represented by spore microorganisms, enterobacteria and yeast. The number of molds is from $110 \mathrm{CFU} / \mathrm{g}$ to $1400 \mathrm{CFU} / \mathrm{g}$. The influence of EMF treatment by electromagnetic fields on the pathogens of strawberry fungal nature was investigated. In the samples treated with EMF ELF, in comparison with the control sample, the number of microorganisms after 14 days of storage was lower. The regularities of the influence of the EMF ELF processing parameters on the development of pathogenic microorganisms of strawberries in experiments and in vivo were revealed. 
ягод земляники сорта «Мармелада» с помощью ЭМП КНЧ с параметрами: частота - 30 Гц, сила тока - 10. А, продолжительность обработки 30 минут оказывает максимальное ингибирующее действие на развитие фитопатогенных микроорганизмов Botrytis cinerea и Rhizopus nigricans.

Ключевые слова: ПРОДУКЦИЯ РАСТЕНИЕВОДСТВА, ХРАНЕНИЕ, ЯГОДЫ, ЗЕМЛЯНИКА, ЭЛЕКТРОМАГНИТНЫЕ ПОЛЯ, МИКРОФЛОРА, ФИТОПАТОГЕНЫ
It was established that the processing of strawberries of the variety «Marmelada» using ELF EMF with parameters: frequency $-30 \mathrm{~Hz}$, current strength -10 . A, processing time -30 minutes has the maximum inhibitory effect on the development of phytopathogenic microorganisms Botrytis cinerea and Rhizopus nigricans.

Key words: PLANT PRODUCTS, STORAGE, BERRIES, STRAWBERRY, ELECTROMAGNETIC FIELDS, MICROFLORA, PHYTOPATHOGENS

Введение. Контроль качества, безопасности и разработка способов обеспечения сохранности продукции растениеводства - актуальная задача, одним из инструментов решения которой является микробиологический контроль продукции растениеводства в процессе выращивания, уборки и хранения, обеспечивающий повышение эффективности агропромышленного комплекса [1-3].

Проблемы микробиальной природы постоянно усиливаются, приобретают особенности ранее не известные человеку. Появление новых бактерий и вирусов снижает эффективность применяемых способов хранения. Микрофлора существенно влияет на скорость и характер изменений, сложных биохимических реакций, протекающих в продукции растениеводства в процессе хранения. Данные процессы нуждаются в дополнительном изучении для того, чтобы научиться целенаправленно управлять ими для сокращения потерь [4].

Фруктовая ткань богата питательными веществами и содержит много влаги, что способствует росту бактерий. Пролиферация бактерий в тканях может достигать опасных уровней, вызывая пищевое отравление и ухудшение органолептических качеств, таких как внешний вид, вкус и запах [5]. Порча ягод является коммерческой проблемой, поскольку видимая плесень и нежелательные запахи приводят к отказу потребителей, 
Плодоводство и виноградарство Юга России № 63(3), 2020 г.

что, в свою очередь, приводит к значительным экономическим потерям и пищевым отходам [6].

Микрофлора ягод земляники представлена разнообразными видами аэробных и факультативно-анаэробных микроорганизмов, плесневых грибов, которые способны вызывать заболевание, ухудшение внешнего вида и порчу ягод. Так, Botrytis cinerea вызывает ботридиоз земляники, возбудитель мучнистой россы Shpaerothta macularis развивается на зрелых ягодах земляники в виде белого налета. Черная плесневидная гниль вызывается сапрофитным грибом Rhizopus nigricans, который за счёт своих специфических морфологических и репродуктивных особенностей способен поразить плоды земляники за 1-2 суток [7].

Для обеспечения максимального снижения потерь при хранении плодово-ягодного сырья биологически активных веществ, сохранения товарного качества используются различные технологии - такие как регулируемая газовая среда, обработка химическими реагентами, микробиологическими препаратами, использование различных физических факторов.

Как правило, достижение высокого урожая и его сохранность достигается с помощью химических фунгицидов. Тем не менее, важные проблемы, связанные с окружающей средой и здоровьем человека, требуют разработки новых методов борьбы с порчей после сбора урожая [8]. Использование синтетических фунгицидов не всегда возможно в период после сбора урожая из-за ограничений по содержанию их остаточных количеств [9]. Продукты, не содержащие пестицидов, пользуются более высоким потребительским спросом [8]. В настоящее время спрос на альтернативные варианты контроля патогенной микрофлоры (микробные антагонисты, природные или обычно считающиеся безопасными соединениями и физические методы) растёт [9-13].

Актуальными остаются исследования по методологии применения электромагнитных полей крайне низких частот (ЭМП КНЧ), с учётом параметров хранения растительной продукции. 
Ранее проведённые исследования показали эффективность применения ЭМП КНЧ для контроля фитопатогенной микрофлоры [14].

При холодильном хранении обработанных в ЭМП КНЧ яблок сорта Айдаред в течение 8 месяцев потери от микробиальной порчи были ниже, чем при хранении контрольных образцов на 11,3 \%, а потери обработанных в ЭМП КНЧ яблок сорта Голден Делишес - на 17,9 \% по сравнению с контрольными образцами. При хранении обработанных в ЭМП КНЧ груш сорта Конференция в течение 7 месяцев потери от микробиальной порчи были ниже, чем при хранении контрольного образца на 12,9 \% [15].

При хранении моркови столовой при $\mathrm{t}=+(25 \pm 1){ }^{\circ} \mathrm{C}(21$ день $)$ количество бактериальной микрофлоры в образцах, обработанных электромагнитными полями крайне низких частот (параметры частота - 28 Гц, время обработки - 5 минут, магнитная индукция - 12 мТл) и биопрепаратом Витаплан (концентрация - $10^{6} \mathrm{KOE} / г$, расход 2,5 мл/кг), снизилось - в 2,1 раза. Количество плесневых грибов - в 1,5 раз [16].

В связи с этим, была выдвинута гипотеза о возможности контроля патогенных микроорганизмов, вызывающих заболеваемость ягод земляники при помощи ЭМП КНЧ.

Цель исследований - изучение влияния ЭМП КНЧ на патогенные микроорганизмы, вызывающие заболеваемость ягод земляники с целью сохранения товарного качества ягод и увеличения сроков их хранения.

Задачи исследований:

- изучить состав микрофлоры земляники;

- исследовать влияние обработки электромагнитными полями КНЧ на патогены земляники грибковой природы;

- выявить закономерности влияния параметров обработки ЭМП КНЧ на развитие патогенных микроорганизмов земляники in vivo. 
Плодоводство и виноградарство Юга России № 63(3), 2020 г.

Объекты и методы исследований. Лабораторные исследования выполняли на базе отдела хранения и комплексной переработки сельскохозяйственного сырья КНИИХП - филиал ФГБНУ СКФНЦСВВ.

Исследования проводили в соответствии с ГОСТ 31904-2012, 10444.12-2013, 10444.15-94, 26669-85 [17-20]; методы визуальной диагностики (осмотр симптомов, фенотипических признаков фитопатогенов), микроскопии (изучение фенотипа спор и мицелия грибов, бактерий, пораженных тканей), выделения чистой культуры фитопатогена и разработанные авторские методики.

Для проведения исследований in vivo были приготовлены суспензии Botrytis cinerea и Rhizopus nigricans с концентрацией $10^{2}$ КОЕ/мл. Суспензии наносили на ягоды земляники с помощью микродозатора в количестве 0,01 мл, заражая по 40 штук для каждого варианта обработки. После нанесения суспензий патогенов, ягоды подвергались обработке ЭМП КНЧ.

После обработки ягоды помещались в контейнеры и хранились при температуре $+(0 \ldots 1){ }^{\circ} \mathrm{C}$ в течение 7 суток.

Все экспериментальные исследования проводились в трехкратной повторности (отклонение между параллельными определениями допускалось не более 5 \%). Математическую обработку экспериментальных данных проводили методом описательной статистики и дисперсионного анализа, используя пакеты программ Microsoft Excel и Statistica.

Обсуждение результатов. На первом этапе исследований было установлено, что естественная микрофлора исследуемых ягод земляники представлена мезофилными аэробными и факультативно-анаэробными микроорганизмами (МАФАнМ) и плесневыми грибами.

Количество МАФАнМ на исследуемых ягодах варьировало в интервале от $5000 \mathrm{KOЕ/г} \mathrm{до} 12000 \mathrm{KOЕ/г.} \mathrm{КМАФАнМ} \mathrm{были} \mathrm{представлены} \mathrm{спо-}$ ровыми микроорганизмами ( $\sim 69 \%)$, энтеробактериями ( $15 \%)$, и дрож- 
Плодоводство и виноградарство Юга России № 63(3), 2020 г.

жами ( 16 \%). Количество плесеней колебалось от $110 \mathrm{KOE} / \Gamma$ до $1400 \mathrm{KOE} / г$.

На следующем этапе изучали влияние параметров обработки ягод земляники ЭМП КНЧ. Для этого образцы земляники сорта Мармелада подвергали воздействию ЭМП КНЧ, варьируя параметры обработки: вариант № $1-20$ Гц, 15 A, 30 минут; вариант № 2 - 30 Гц, 10 А, 30 минут; вариант № 3 - 40 Гц, 5 А, 30 минут и закладывали их на хранение при температуре $+(0 \ldots 1){ }^{\circ} \mathrm{C}$.

Количество микроорганизмов на поверхности исследуемых образцов определяли до обработки, через 30 минут после обработки и через 14 дней после хранения.

В таблице 1 представлены данные, иллюстрирующие изменение микробиологических показателей ягод земляники в зависимости от способов обработки ЭМП КНЧ.

Таблица 1 - Влияние режима обработки на количество микроорганизмов в процессе хранения земляники при температуре $+(0 \ldots 1){ }^{\circ} \mathrm{C}$.

\begin{tabular}{|c|c|c|c|c|c|c|}
\hline \multirow{2}{*}{ 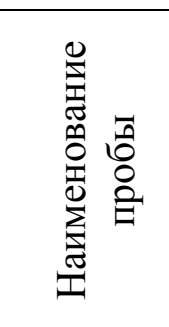 } & \multicolumn{3}{|c|}{$\begin{array}{c}\text { Количество МАФАнМ, } \\
\text { КОЕ/г }\end{array}$} & \multicolumn{3}{|c|}{$\begin{array}{c}\text { Количество плесеней, } \\
\text { КОЕ/г }\end{array}$} \\
\hline & $\begin{array}{c}\text { перед } \\
\text { закладкой } \\
\text { на } \\
\text { хранение }\end{array}$ & $\begin{array}{c}30 \text { минут } \\
\text { после } \\
\text { обработки }\end{array}$ & $\begin{array}{c}14 \text { дней } \\
\text { хранения, } \\
+(0 \ldots 1)^{\circ} \mathrm{C}\end{array}$ & $\begin{array}{c}\text { перед } \\
\text { закладкой } \\
\text { на } \\
\text { хранение }\end{array}$ & $\begin{array}{c}30 \text { минут } \\
\text { после } \\
\text { обработки }\end{array}$ & $\begin{array}{c}\text { после } \\
14 \text { дней } \\
\text { хранения, } \\
+(0 \ldots 1)^{\circ} \mathrm{C}\end{array}$ \\
\hline контроль & $6,5 \times 10^{3}$ & $6,5 \times 10^{3}$ & $150 \times 10^{3}$ & 280 & 280 & 4000 \\
\hline $\begin{array}{l}\text { вариант } \\
\text { № } 1\end{array}$ & $6,5 \times 10^{3}$ & $6,1 \times 10^{3}$ & $9,5 \times 10^{3}$ & 280 & 225 & 950 \\
\hline $\begin{array}{l}\text { вариант } \\
\text { № } 2 \\
\end{array}$ & $6,5 \times 10^{3}$ & $5,0 \times 10^{3}$ & $7,2 \times 10^{3}$ & 280 & 200 & 650 \\
\hline $\begin{array}{l}\text { вариант } \\
\text { № } 3\end{array}$ & $6,5 \times 10^{3}$ & $5,7 \times 10^{3}$ & $8,3 \times 10^{3}$ & 280 & 250 & 1200 \\
\hline
\end{tabular}

Из данных представленных в таблице видно, что через 30 минут после обработки ЭМП КНЧ всеми тремя вариантами значительного снижения количества МАФАнМ и плесеней не происходило. После 14 дней хранения в контрольных образцах количество МАФАнМ увеличилось 
в 23 раза, а количество плесеней - в 14 раз. В обработанных образцах по сравнению с контрольным образцом количество микроорганизмов через 14 дней хранения было ниже:

- вариант № 1: МАФАнМ - в 15 раз, плесени - 4,2 раза;

- вариант № 2: МАФАнМ - 20,8 раз, плесени - 6,2 раза;

- вариант № 3: МАФАнМ - 18 раз, плесени - 3,3 раза.

На следующем этапе исследовали влияние параметров обработки ЭМП КНЧ на развитие поражения от исследуемых фитопатогенов на ягодах земляники в оптах in vivo.

В таблице 2 представлены результаты, отражающие развитие фитопатогенов на ягодах земляники, хранившихся при температуре $+(0 \ldots 1){ }^{\circ} \mathrm{C}$ в течение 7 суток.

Таблица 2 - Влияние обработки ягод земляники ЭМП КНЧ на развитие фитопатогенов в процессе хранения в течение 7 суток при $+(0 \ldots 1){ }^{\circ} \mathrm{C}$

\begin{tabular}{|l|c|c|}
\hline \multirow{2}{*}{$\begin{array}{c}\text { Исследуемые } \\
\text { фитопатогены }\end{array}$} & \multicolumn{2}{|c|}{ Площадь пораженной ткани, мм } \\
\cline { 2 - 3 } & контроль & обработка \\
\hline Botrytis cinerea & отариант (20 Гц, $15 \mathrm{~A}, 30$ минут) \\
\hline Rhizopus nigricans & от 1,7 до 27 & от 1,7 до 10 \\
\hline \multicolumn{3}{|c|}{ 2 вариант (30 Гц, $10 \mathrm{~A}, 30$ минут) } \\
\hline Botrytis cinerea & от 2 до 25 & от 1 до 8 \\
\hline Rhizopus nigricans & от 1,7 до 27 & от 1,2 до 9 \\
\hline & 3 вариант (40 Гц, $5 \mathrm{~A}, 30$ минут) \\
\hline Botrytis cinerea & от 2 до 25 & от 2 до 12 \\
\hline Rhizopus nigricans & от 1,7 до 27 & от 1,5 до 18 \\
\hline
\end{tabular}

Анализируя полученные данные можно сделать вывод о том, что в опытах in vivo наибольшее ингибирующее действие на развитие фитопатогенные микроорганизмы Botrytis cinerea и Rhizopus nigricans оказывает обработка ЭМП КНЧ с параметрами: частота - 30 Гц, сила тока - 10 А, продолжительность обработки - 30 минут (2 вариант). 
Плодоводство и виноградарство Юга России № 63(3), 2020 г.

Bbывды. В процессе исследования изучен состав микрофлоры земляники, установлено, что количество МАФАнМ на ягодах земляники сорта «Мармелада» составило от $5000 \mathrm{KOE} / г$ до 12000 КОЕ/Г. КМАФАнМ в основном представлены споровыми микроорганизмами ( 69 \%), энтеробактериями ( $15 \%)$ и дрожжами ( $16 \%)$. Количество плесеней от $110 \mathrm{KOE} /$ д до $1400 \mathrm{KOE} / \Gamma$.

Исследовано влияние обработки электромагнитными полями КНЧ на патогены земляники грибковой природы.

В обработанных образцах по сравнению с контрольным образцом количество микроорганизмов через 14 дней хранения было ниже

- вариант № 1: МАФАнМ - в 15 раз, плесени - 4,2 раза;

- вариант № 2: МАФАнМ - 20,8 раз, плесени - 6,2 раза;

- вариант № 3: МАФАнМ - 18 раз, плесени - 3,3 раза.

Выявлены закономерности влияния параметров обработки ЭМП КНЧ на развитие патогенных микроорганизмов земляники в опытах и in vivo.

Установлено, что максимальное ингибирующее действие на развитие фитопатогенных микроорганизмов Botrytis cinerea и Rhizopus nigricans оказывает обработка ягод земляники сорта Мармелада с помощью ЭМП КНЧ с параметрами: частота - 30 Гц, сила тока - 10 А, продолжительность обработки - 30 минут.

\section{Литература}

1. Oliveira M. et al. 2015. Application of modified atmosphere packaging as a safety approach to fresh-cut fruits and vegetables. - Trends in Food Science \& Technology. - № 46. - pp. 13-26.

2. Sandhya, -2010 . Modified atmosphere packaging of fresh produce: Current status and future needs. - LWT. Food Science and Technology.- № 43. - pp. 381-392.

3. Siddiq M., Sogi D., Dolan K., 2013. Antioxidant properties, total phenolics, and quali-ty of fresh-cut «Tommy Atkins» mangoes as affected by different pre-treatments. LWT. Food Science and Technology. - № 53. - pp. 156-162.

4. Alexandre E.M.C., Santos-Pedro D.M., Brandão T.R.S., Silva C.L.M., 2011. Influence of aqueous ozone, blanching and combined treatments on microbial load of red bell peppers, strawberries and watercress. - J. Food Eng. - № 105. - pp. 277-282.

5. Alwi N.A., Ali A., 2014. Reduction of Escherichia coli O157, Listeria monocytogenes and Salmonella enteric sv. Typhimurium populations on fresh-cut bell pepper using gaseous ozone. - Food Control. - № 46. - pp. 304-311. 2 
6. Arango J., Rubino M., Auras R., Gillett J., Schilder A., Grzesiak A.L., 2016. Evaluation of chlorine dioxide as an antimicrobial against Botrytis cinerea in California strawberries. - Food Packag. Shelf Life. - № 9. - pp. 45-54.

7. Котляров В.В. Бактериальные болезни культурных растений: учебное пособие. Краснодар: КубГАУ, 2008. 324 с.

8. Mari M., Bautista-Baños S., Sivakumar D., 2016. Decay control in the postharvest system: role of microbial and plant volatile organic compounds. - Postharvest Biol. Technol. - № 122. - pp. 70-81.

9. Sanzani S.M., Reverberi M., Geisen R., 2016. Mycotoxins in harvested fruits and vegetables: insights in producing fungi, biological role, conducive conditions, and tools to manage postharvest contamination. - Postharvest Biol. Technol. - № 122. - pp. 95-105.

10. Davidson P.M., Zivanovic S., 2003. The use of natural antimicrobials. Food Preservation Techniques. - Zeuthen P., Bogh-Sorensen L. (Eds.). -Woodhead Publishing Ltd., Cambridge. - pp. 5-30.

11. Nithya V., Murthy K., Halami P.M., 2013. Development and application of active films for food packaging using antibacterial peptide of Bacillus licheniformis. - Me1 J. Appl. Microbiol. - № 115. - pp. 475-483.

12. Gálvez A., Abriouel H., López R.L., Omar N.B., 2007. Bacteriocin-based strategies for food biopreservation. - Int. J. Food Microbiol.- № 120. - pp. 51-70.

13. Li M. et al., 2014. Effects of bacteriophage on the quality and shelf life of Paralichthys olivaceus during chilled storage. - J. Sci. Food Agric.- № 94. - pp. 1657-1662.

14. Pershakova T.V., Kupin G.A., Mihaylyuta L.V., Babakina M.V., Gorlov S.M., Lisovoy V.V., 2018. Investigation of the influence of an extremely low-frequency electromagnetic field on carrot phytopathogens in-vivo and in-vitro. - Journal of Pharmaceutical Sciences and Research.- №, 8 (10). - pp. 1897-1901.

15. Исследование влияния электромагнитных полей на изменение микробиальной обсемененности фруктов в процессе хранения / Лисовой В.В. и др. // Политематический сетевой электронный научный журнал Кубанского Государственного Аграрного Университета. 2017. № 126. С. 843-854.

16. Pershakova T.V., Kupin G.A., Mihaylyuta L.V., Babakina M.V., Panasenko E.Y., Viktorova E.P., 2018. Investigation of antagonistic properties of bacteria bacillus subtilis against carrot phytopathogenes in vitro and in vivo experiments. - Journal of pharmaceutical sciences and research. - 10 (6). - pp. 1619-1622.

17. ГОСТ 31904-2012. Продукты пищевые. Методы отбора проб для микробиологических испытаний. - Введ. 01.07.2013. - М.: Стандартинформ, 2014. - 8 с.

18. ГОСТ 26669-85. Продукты пищевые и вкусовые. Подготовка проб для микробиологических анализов. - Введ. 01.07.1986. - М.: Изд-во стандартов, 1986. - 9 с.

19. ГОСТ 10444.15-94. Продукты пищевые. Методы определения количества мезофильных аэробных и факультативно-анаэробных микроорганизмов. - Введ. 01.01.1996. - М.: Стандартинформ, 2010. - 7 с.

20. ГОСТ 10444.12-2013. Микробиология пищевых продуктов и кормов для животных. Методы выявления и подсчета количества дрожжей и плесневых грибов. Введ. 01.07.2015. - М.: Стандартинформ, 2014. - 12 с.

\section{References}

1. Oliveira M. et al. 2015. Application of modified atmosphere packaging as a safety approach to fresh-cut fruits and vegetables. - Trends in Food Science \& Technology. - № 46. - pp. 13-26.

2. Sandhya, - 2010. Modified atmosphere packaging of fresh produce: Current status and future needs. - LWT. Food Science and Technology.- № 43. - pp. 381-392. 
3. Siddiq M., Sogi D., Dolan K., 2013. Antioxidant properties, total phenolics, and quali-ty of fresh-cut «Tommy Atkins» mangoes as affected by different pre-treatments. LWT. Food Science and Technology. - № 53. - pp. 156-162.

4. Alexandre E.M.C., Santos-Pedro D.M., Brandão T.R.S., Silva C.L.M., 2011. Influence of aqueous ozone, blanching and combined treatments on microbial load of red bell peppers, strawberries and watercress. - J. Food Eng. - № 105. - pp. 277-282.

5. Alwi N.A., Ali A., 2014. Reduction of Escherichia coli O157, Listeria monocytogenes and Salmonella enteric sv. Typhimurium populations on fresh-cut bell pepper using gas-eous ozone. - Food Control. - № 46. - pp. 304-311. 2

6. Arango J., Rubino M., Auras R., Gillett J., Schilder A., Grzesiak A.L., 2016. Evaluation of chlorine dioxide as an antimicrobial against Botrytis cinerea in California strawberries. - Food Packag. Shelf Life. - № 9. - pp. 45-54.

7. Kotlyarov V.V. Bakterial'nye bolezni kul'turnyh rastenij: uchebnoe posobie. Krasnodar: KubGAU, 2008. - 324 s.

8. Mari M., Bautista-Baños S., Sivakumar D., 2016. Decay control in the postharvest system: role of microbial and plant volatile organic compounds. - Postharvest Biol. Technol. - № 122. - pp. 70-81.

9. Sanzani S.M., Reverberi M., Geisen R., 2016. Mycotoxins in harvested fruits and vegetables: insights in producing fungi, biological role, conducive conditions, and tools to manage postharvest contamination. - Postharvest Biol. Technol. - № 122. - pp. 95-105.

10. Davidson P.M., Zivanovic S., 2003. The use of natural antimicrobials. Food Preservation Techniques. - Zeuthen P., Bogh-Sorensen L. (Eds.). -Woodhead Publishing Ltd., Cambridge. - pp. 5-30.

11. Nithya V., Murthy K., Halami P.M., 2013. Development and application of active films for food packaging using antibacterial peptide of Bacillus licheniformis. - Me1 J. Appl. Microbiol. - № 115. - pp. 475-483.

12. Gálvez A., Abriouel H., López R.L., Omar N.B., 2007. Bacteriocin-based strategies for food biopreservation. - Int. J. Food Microbiol.- № 120. - pp. 51-70.

13. Li M. et al., 2014. Effects of bacteriophage on the quality and shelf life of Paralichthys olivaceus during chilled storage. - J. Sci. Food Agric.- № 94. - pp. 1657-1662.

14. Pershakova T.V., Kupin G.A., Mihaylyuta L.V., Babakina M.V., Gorlov S.M., Lisovoy V.V., 2018. Investigation of the influence of an extremely low-frequency electromagnetic field on carrot phytopathogens in-vivo and in-vitro. - Journal of Pharmaceutical Sciences and Research.- №, 8 (10). - pp. 1897-1901.

15Issledovanie vliyaniya elektromagnitnyh polej na izmenenie mikrobial'noj obsemenennosti fruktov v processe hraneniya / Lisovoj V.V. i dr. // Politematicheskij setevoj elektronnyj nauchnyj zhurnal Kubanskogo Gosudarstvennogo Agrarnogo Universiteta. 2017. № 126. s. 843-854.

16. Pershakova T.V., Kupin G.A., Mihaylyuta L.V., Babakina M.V., Panasenko E.Y., Viktorova E.P., 2018. Investigation of antagonistic properties of bacteria bacillus subtilis against carrot phytopathogenes in vitro and in vivo experiments. - Journal of pharmaceutical sciences and research. - 10 (6). - pp. 1619-1622.

17. GOST 31904-2012. Produkty pishchevye. Metody otbora prob dlya mikrobiologicheskih ispytanij. - Vved. 01.07.2013. - M.: Standartinform, 2014. - $8 \mathrm{~s}$.

18. GOST 26669-85. Produkty pishchevye i vkusovye. Podgotovka prob dlya mikrobiologicheskih analizov. - Vved. 01.07.1986. - M.: Izd-vo standartov, 1986. - 9 s.

19. GOST 10444.15-94. Produkty pishchevye. Metody opredeleniya kolichestva mezofil'nyh aerobnyh i fakul'tativno-anaerobnyh mikroorganizmov. - Vved. 01.01.1996. - M.: Standartinform, 2010. $-7 \mathrm{~s}$.

20. GOST 10444.12-2013. Mikrobiologiya pishchevyh produktov i kormov dlya zhivotnyh. Metody vyyavleniya i podscheta kolichestva drozhzhej i plesnevyh gribov. - Vved. 01.07.2015. - M.: Standartinform, 2014. - 12 s. 